\title{
The influence of commercial primed canvases in the manifestation of metal soaps protrusions in Georgia O'Keeffe's oil paintings
}

Annette S. Ortiz Miranda ${ }^{1}$, Dale Kronkright ${ }^{2}$ and Marc Walton ${ }^{1^{*}}$ (1)

\begin{abstract}
During a routine condition survey in 2007 at the Georgia O'Keeffe Museum in Santa Fe, micro-protrusions were found scattered across the surfaces of the artist's oil paintings produced between 1920 and 1950. In many of her works, including Pedernal (1941) and A Man from the Desert (1941), lead soaps were found aggregated the painting surface, forcing the surrounding paint to deform into pin-sized protrusions. The structure and composition of the protrusions was analyzed to determine why they formed. Microsamples were removed from four of O'Keeffe's paintings and investigated using a combination of SEM-EDX, GC-MS, and FT-IR. The combined GC-MS and FT-IR results indicate that the protrusions contain primarily lead carboxylates. The results obtained for a series of ground samples removed from four different paintings were then compared with samples collected from a commercially pre-primed canvas roll found in the artist's house in Ghost Ranch, NM. We identified two different types of canvases: i) a commercially preprimed canvas and ii) artist primed canvas. This commercially pre-primed canvas roll has a similar morphology to the ground layers in her paintings that contain protrusions additionally these grounds were found to contain an excess of free fatty acids and metal carboxylates (lead soaps) based on a comparison to canvases the artist primed herself. Based on the analytical results from the four paintings and the commercial pre-primed canvas, we concluded that the artist's use of this particular commercially pre-primed canvas between 1920 and 1950 play an important role in the observed micro-protrusions.
\end{abstract}

Keywords: Georgia O'Keeffe, SEM-EDX, FT-IR, GC-MS, Metal soaps, Free fatty acids, Silylation, Oil painting

\section{Introduction}

In 2007 the Georgia O'Keeffe Museum in Santa Fe, NM undertook a condition survey of their collection to broadly explore deterioration mechanisms in the artist's paintings. From this survey, it was found that many of her works produced between 1920 and 1950 had disfiguring micro-protrusions scattered across their surfaces as may be observed in Fig. 1b and d. These protrusions range in size from 30 to $200 \mu \mathrm{m}$ and have a characteristic appearance of metal carboxylate that have aggregated just below

\footnotetext{
*Correspondence: marc.walton@northwestern.edu

${ }^{1}$ Center for the Scientific Studies in the Arts, Northwestern University, Evanston, IL, USA

Full list of author information is available at the end of the article
}

the top surface [1]. Based on anecdotal evidence, these soap features started to form only 20 years after the completion of the paintings when the artist herself asked the pioneering conservators Caroline and Sheldon Keck to help diagnose their cause. Recently formed soap protrusions on O'Keeffe's artworks, evident from protrusions forming under areas of retouching added within the last decade (Fig. 1c, d), suggest ongoing deterioration through the present day. Thus, active soap formation remains a significant concern for the long-term stability of these artworks.

Drying oils in paintings are composed of triglyceride molecules with unsaturated fatty acid chains that polymerize when exposed to oxygen, forming a rigid crosslinked network once "cured" [2-4]. Metal soaps
Springer Open

(c) The Author(s) 2020. This article is licensed under a Creative Commons Attribution 4.0 International License, which permits use, sharing, adaptation, distribution and reproduction in any medium or format, as long as you give appropriate credit to the original author(s) and the source, provide a link to the Creative Commons licence, and indicate if changes were made. The images or other third party material in this article are included in the article's Creative Commons licence, unless indicated otherwise in a credit line to the material. If material is not included in the article's Creative Commons licence and your intended use is not permitted by statutory regulation or exceeds the permitted use, you will need to obtain permission directly from the copyright holder. To view a copy of this licence, visit http://creativeco mmons.org/licenses/by/4.0/. The Creative Commons Public Domain Dedication waiver (http://creativecommons.org/publicdomain/ zero/1.0/) applies to the data made available in this article, unless otherwise stated in a credit line to the data. 

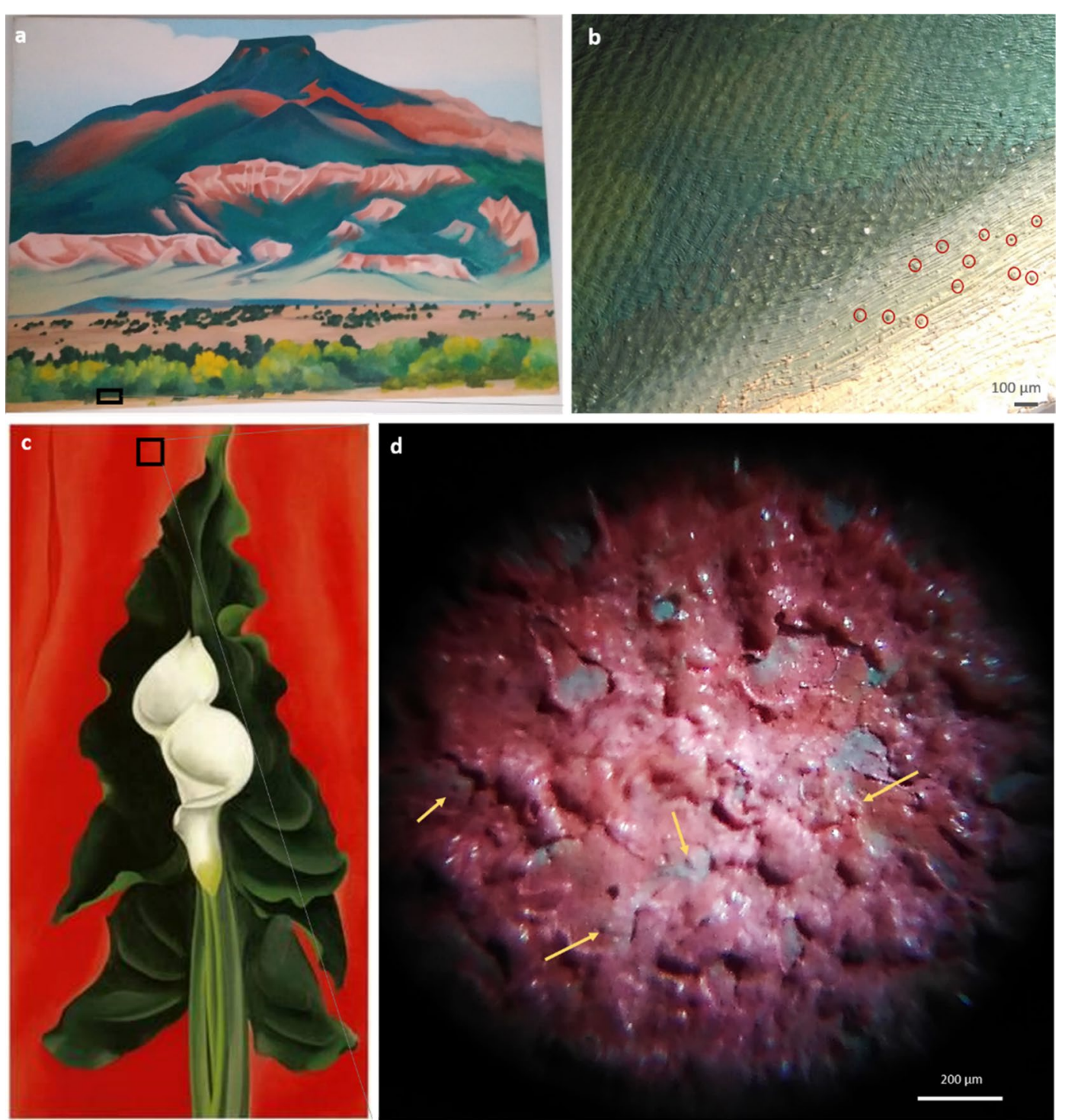

Fig. 1 a Pedernal (1941), oil on canvas, b Detail of the metal soap protrusions in Pedernal (1941), c Calla Lily on Red (1928) and d) detail of Calla Lily on Red (1928) with new protrusions growing under re-painted areas (indicated by arrows), Georgia O'Keeffe Museum, Santa Fe

in these networks form by reaction between long alkyl chain, saturated carboxylic acids (fatty acids), naturally present in the binding media, and $\mathrm{Zn}$ or $\mathrm{Pb}$ oxides or carbonates (white pigments). However, even after the paint is considered sufficiently cured, glyceryl esters may hydrolyze, mediated by the presence of water in the ambient environment, and detach from the polymer network as additional free fatty acids. Hydrolysis reactions in paintings can thus produce a large reserve of free fatty acids available for reaction with metal ions. Despite the common occurrence of such hydrolysis reactions within paintings, the phenomena and the conditions involved in the formation of metal carboxylates soap protrusions are not fully understood [26]. Commonly, such soaps remain where they developed initially without any deleterious effect to the surrounding matrix [5]. This observation has led to a significant amount of recent research attempting to address what reactive forces induce metal carboxylate soaps to sometimes undergo phase segregation [6$8]$. Since their initial discovery $[9,10]$ two decades ago, understanding how, where, and why protrusions occur has become one of the critical research foci in oil painting conservation.

This investigation explores the hypothesis that the soap protrusions formed within O'Keeffe's paintings are associated with changes the artist made to her technique. 
O'Keeffe moved from her teaching position in Texas, at the invitation of the famous photographer and gallerist Alfred Stieglitz to focus on oil painting, arriving to NYC on June 10, 1918. For the next 5 years, O'Keeffe painted in Manhattan, Lake George, and Maine, developing greater fluency with the media and creating a unique form of painting that explores a tension between abstraction and representation of subjects found in, or developed from nature. Beginning in January of 1923, and continuing for the following 8 years, Stieglitz opened an exhibition of 50 to 100 new paintings by O'Keeffe. It is this demand for her oil paintings, in particular in Stieglitz's annual gallery exhibitions of her work, requiring approximately one new painting every week, that forced O'Keeffe to abandon sizing and priming her own canvases. Instead, she increasingly adopted the use of commercially preprimed $^{1}$ canvas. However, coinciding with Stieglitz's death in 1946, the artist refused to participate in annual gallery exhibitions and thus returned to hand-sizing and priming her canvases again.

Commercial pre-primed canvas during this period usually consisted of one or various ground layers containing white pigments and fillers such as lead white, barium white, zinc-white and calcium carbonate which were sometimes amended with plasticizers and other additives (e.g. non-drying oils, honey, glycerin, sugar, soaps) to keep the material composite pliable for longer shelf-lives [11-13, 31, 47]. During the course of this study, such a roll of commercial pre-primed canvas, partially used by O'Keeffe, was found stored in the garage at O'Keeffe's Ghost Ranch, NM. This composite material became of primary interest to our investigation in order to establish its relationship to the lead soap protrusions formations observed on her paintings.

This case study thus characterizes soap protrusion formed on Georgia O'Keeffe paintings with an aim to link how the artist's use of a commercial pre-primed canvas contributed to the degradation state of her paintings and influenced aggregation of soaps. Data are presented to trace the origin of the reactive components in the multilayered system observed in the grounds used by O'Keeffe. With this aim, the following paintings in the collection of the Georgia O'Keeffe Museum were included in our investigation:

- Storm Cloud, Lake George, 1923, oil on canvas, $18 \times 301 / 8$ inches. Gift of The Burnett Foundation, 2007.1.18.

\footnotetext{
1 The term pre-primed will be used to refer to a canvas with a commercially applied ground layer or layers.
}

- Pedernal, 1941, oil on canvas, $19 \times 301 / 4$ inches. Gift of The Georgia O'Keeffe Foundation, 2006.5.172.

- A Man from the Desert, 1941, oil on canvas, 16 15/16 $\times 71 / 16$ inches. Gift of The Georgia O'Keeffe Foundation, 2006.5.167.

- Pink \& Green, 1960, oil on canvas, 30 x 16 inches. Gift of The Burnett Foundation, 1997.6.18.

The selection of the Georgia O'Keeffe paintings included in this study was based on their state of preservation as well as the period of production based on the hypothesis that the artist made significant changes to her studio materials during the years of her annual gallery exhibitions of new paintings, from 1923 to 1946. Samples were collected from four O'Keeffe paintings: Pedernal, $A$ Man from the Desert, Storm Cloud, Lake George and Pink and Green. Two paintings with commercially pre-primed canvases exhibited high amounts of soap protrusions: Pedernal and A Man from the desert produced by the artist during the period (1924-1950). The other two paintings in this study, Storm Cloud, Lake George and Pink and Green, lack protrusions and were painted on artistsprimed canvases. A sample from a pre-primed commercial canvas roll used by the artist was also included in this study.

\section{Results and discussion}

\section{Sem-edx}

Cross sections of ground samples taken from Pedernal and A Man from the Desert (1941), which were painted before Stieglitz's death in 1946 and O'Keeffe's subsequent permanent move to New Mexico in 1949, are presented in Fig. 2a-d. The optical (Fig. 2a and c) and backscattered electron (BSE) micrographs (Fig. $2 b$ and d) show that the samples are composed of two layers which are labeled here as ground (1) for the lower layer that consists mainly of calcium-rich particles with some lead-based agglomerates, and a preparation layer ${ }^{2}(2)$, primarily composed of lead particles with a few calcium particles (indicated by the lower Z-contrast), that is in contact with the visible paint layers immediately above. Energy dispersive $\mathrm{X}$-ray microanalysis (EDX) analysis reveals the spatial co-occurrence of $\mathrm{Ba}$ and $\mathrm{S}$, indicating the presence of the mineral barite $\left(\mathrm{BaSO}_{4}\right)$ evenly distributed through both layers (Additional file 1). Apart from the difference in chemical composition of each respective layer, there are some morphological differences between the ground and preparation layers. For example, the pigment distribution in the preparation layer shows an abundance of small

\footnotetext{
2 The term preparation layer will be used to indicate the presence of an intermediate layer between the ground and paint (design) layer.
} 

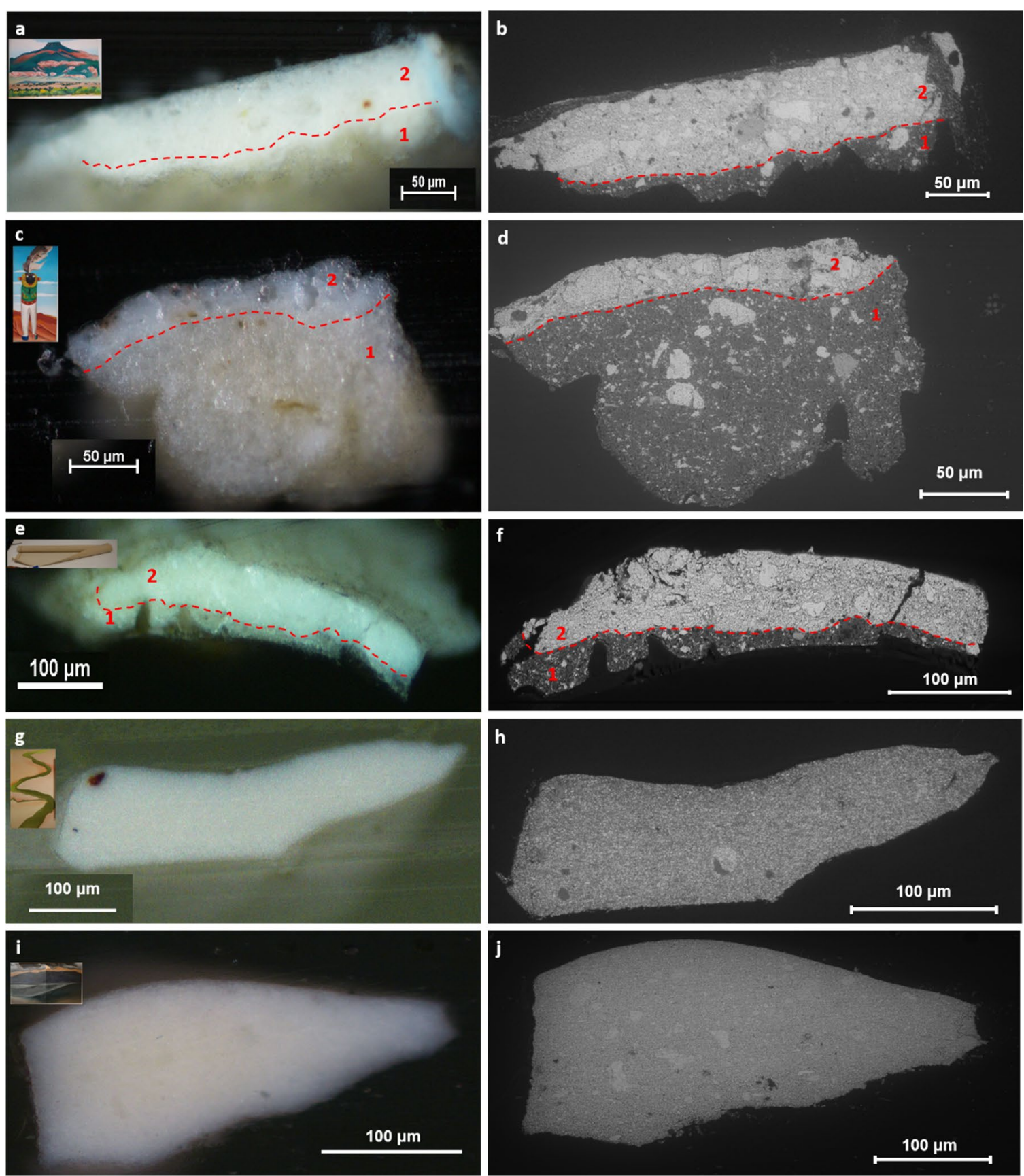

Fig. 2 Incident light and BSE images of: Pedernal (1941) (a, b), A Man from the Desert (1941) (c, d), commercial pre-primed canvas roll (e, f), Pink and Green (1960) (g, h) and Storm Cloud, Lake George (1923) (i, j)

individual lead-based pigment particles that surround larger agglomerates of this material (Fig. 3) creating lowdensity regions and micro-pores between the particles.
In a semipermeable system like a painting, the presence of these agglomerated particles results in a breccia-like ${ }^{3}$ [46] appearance and provides the layer with porosity. The cross-section prepared from the commercial pre-primed 

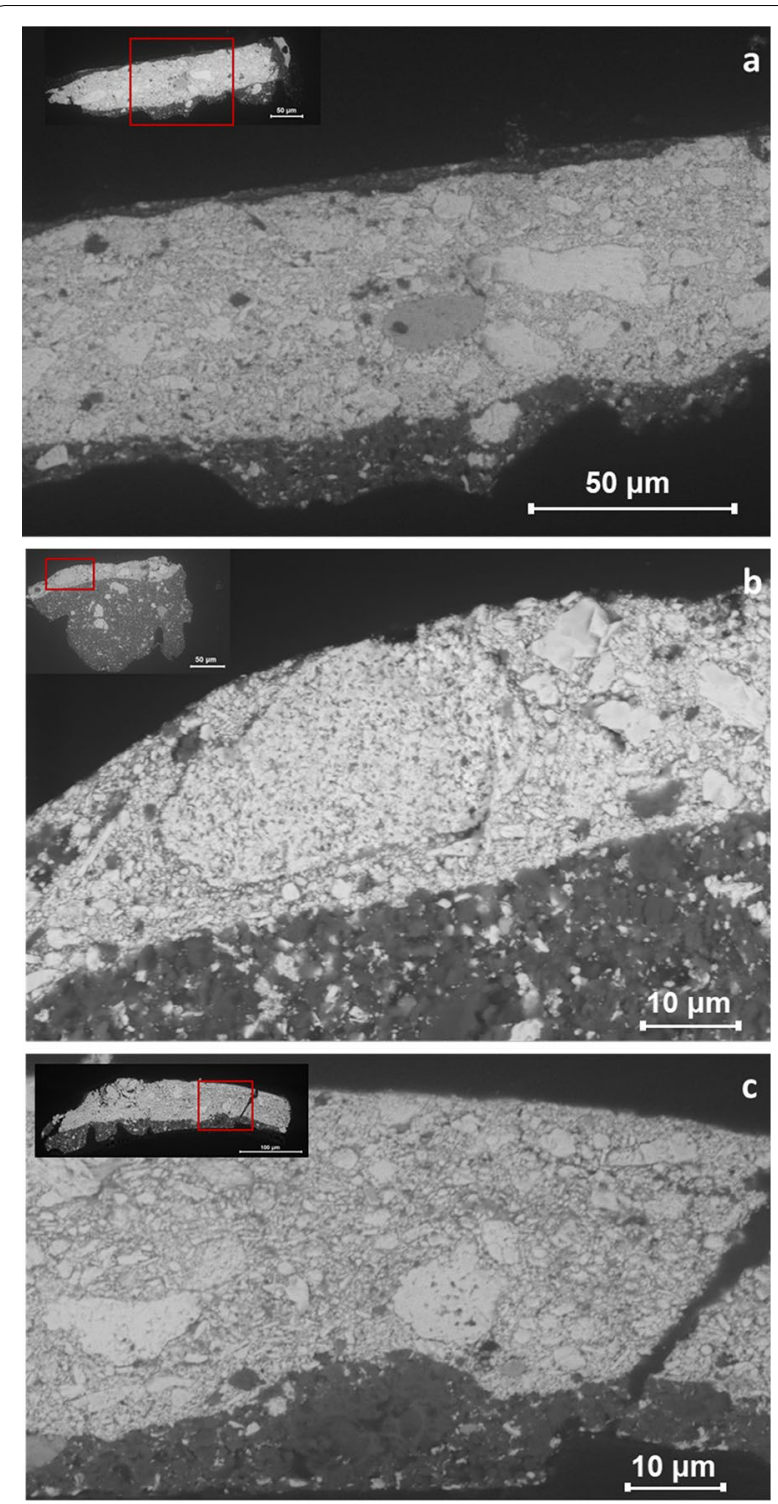

Fig. 3 BSE detail image of the preparation layer "breccia-like" aspect obtained for: Pedernal (1941) (a), A Man from the Desert (1941) (b), un-painted commercial pre-primed canvas roll (c)

canvas roll, in Fig. 2e and $\mathrm{f}$, shares the same identical elemental compositions, layer structures, and pigment size/distributions as Pedernal and A Man from the Desert indicating that these paintings were prepared on the commercially pre-primed canvas, a fact confirmed by the continuous priming layer under the original tacks along the tacking edges of both paintings. These characteristics are thus "fingerprints" for O'Keeffe's use of this commercial material on these works of art.

In contrast, the ground samples collected from Storm Cloud, Lake George (1923) and Pink and Green (1960), made both before and after the annually gallery exhibitions of new work of O'Keeffe's oil paintings from 1923 to 1946 , exhibit a single ground layer (Fig. $2 \mathrm{~g}-\mathrm{j}$ ). The BSE images (Fig. $2 \mathrm{~h}$ and $\mathrm{j}$ ) of these sections reveal differences in morphology and pigment size/distribution of the lead pigment particles in comparison to the gallery exhibition-era paintings with lead particle sizes more homogeneous, evenly distributed, and compact. These findings support the archival information about the artist's use of commercial pre-primed canvas during the years of annual exhibitions of new work from 1923 to 1946.

As is observable to the naked eye, both Pedernal and A Man from the Desert exhibit protrusions with a "waxy" appearance or pinpoint losses where there was once a protrusion (Fig. 1b). Cross-sections of these protrusions from Pedernal and A Man from the Desert are presented in Fig. 4. The optical image of a cross section from the sky of Pedernal and the corresponding BSE image is presented in Fig. 4a, b. From these images three different layers are visible: in addition to the ground and preparation layers there is a top layer composed of a mixture of $\mathrm{Pb}$ and $\mathrm{Co}$ associated with a cobalt aluminate pigment (labelled 3 in Fig. 4a, b). The soap aggregate in Fig. 4b has a low Z-contrast due to the fact that the region is rich in organic material studded with occasional lead white pigment particles. Another observation is that the soap protrusion partially ripped during the process of microtoming (indicated by the arrows in Fig. 4b) which provides a qualitative indication of the softness of the soap-rich region. A similar structure is observed in the cross section of A Man from the Desert (Fig. 4c. d) where the same three layers can be identified. The soap protrusion area in the right upper corner of Fig. $4 \mathrm{~d}$ abuts the preparation layer. It is notable that the soap protrusion extends through the top layer into the preparation layer densely packed with lead-based pigment agglomerates (indicated with an asterisk in Fig. 4d) and in direct contact with the soap protrusion aggregate in the upper right corner of the sample (square in Fig. 4d). Similar composition was observed in the soap protrusion collected from the un-painted commercial pre-primed canvas roll rich in organic material indicated by the low Z-contrast (Fig. 5). In this cross section nearly all the lead white pigment has dissolved leaving only a few intact pigment particles within the protrusion (Fig. 5b). EDS analysis confirms that the remaining particles are lead white pigment (Fig. 5c). The organic-rich area of both soaps does not exhibit a mineralized core (crystalline material), as has been observed previously for crystalline lead soap protrusions $[16,17]$, possibly due 

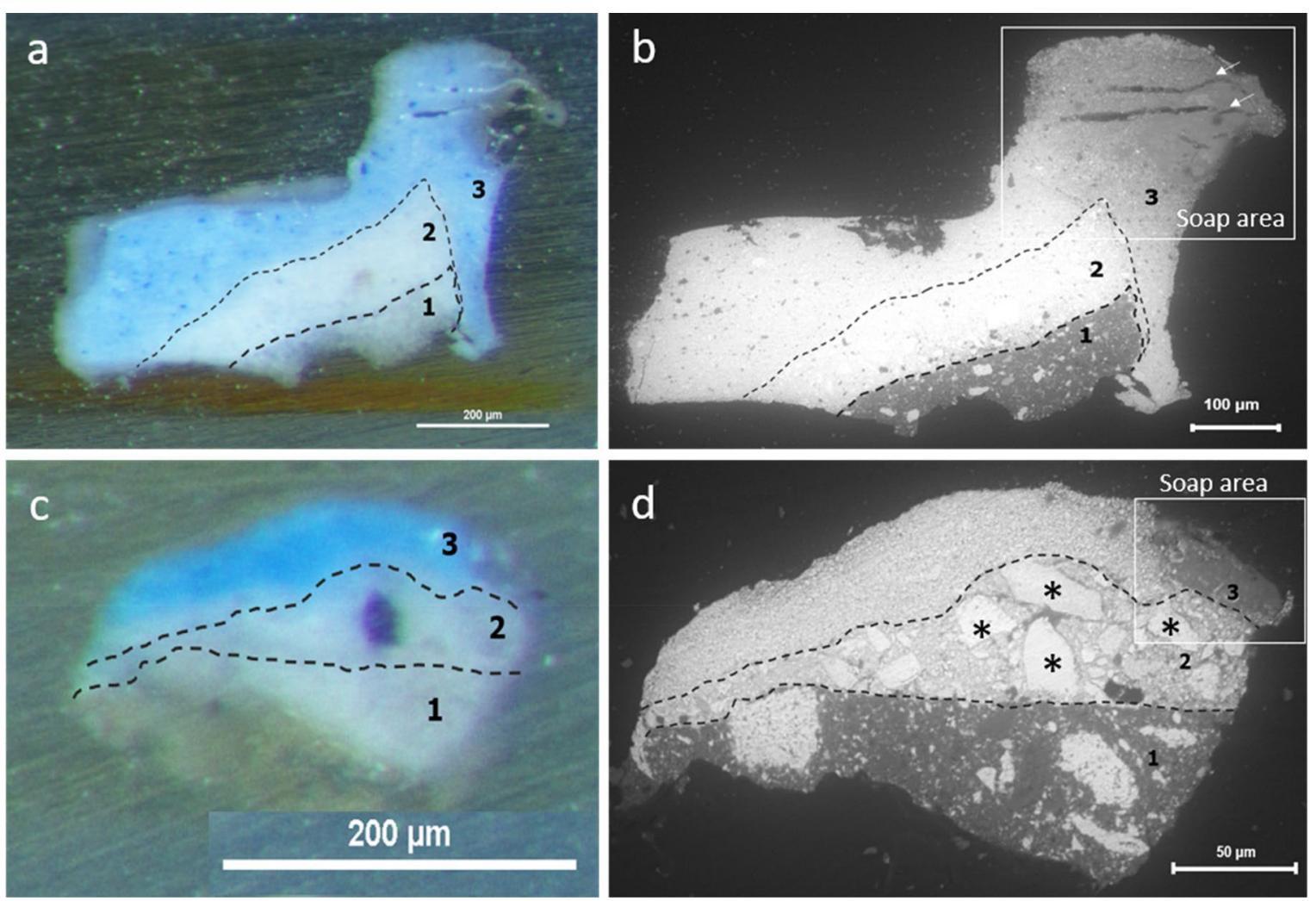

Fig. 4 Darkfield optical images and BSE images of: Pedernal (a, b) and A Man from the Desert (c, d). Samples layer composition: ground layer (1), preparation layer (2) and visible layer (3). Lead-based white pigment agglomerates are indicated with an asterisk
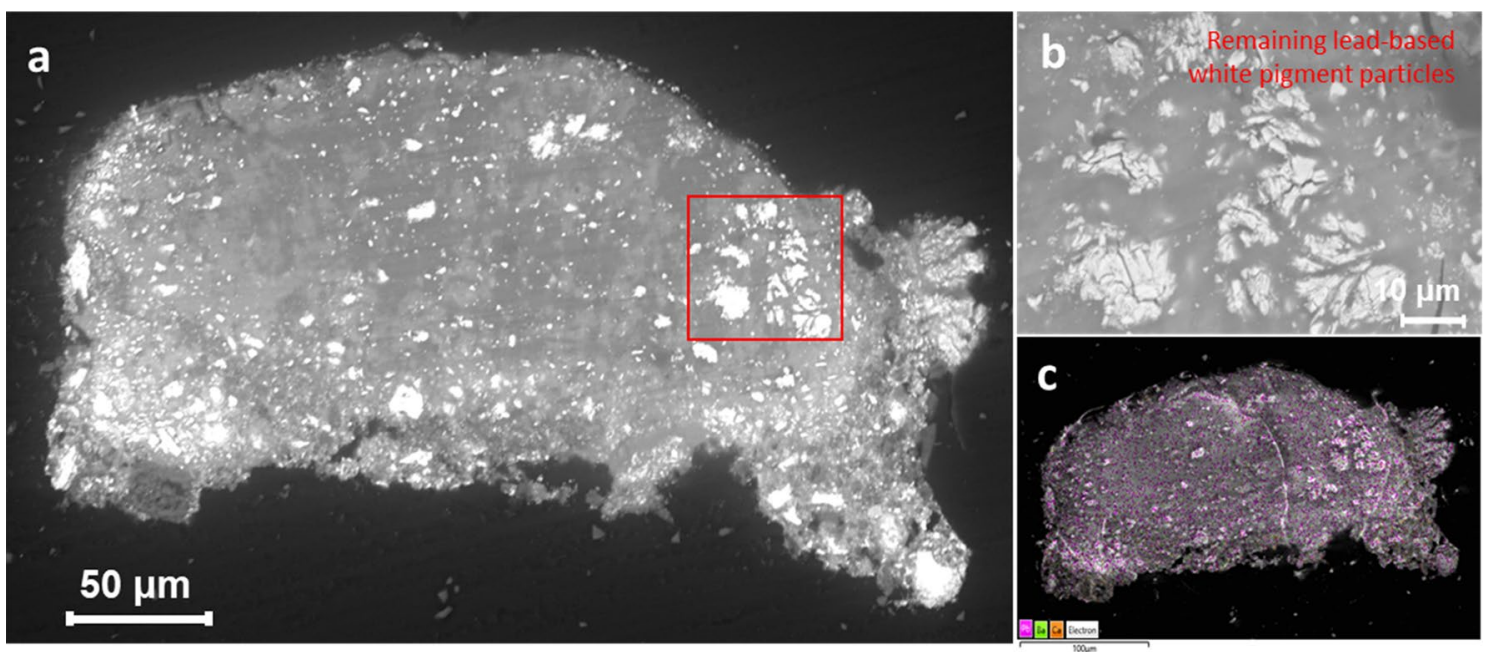

Fig. 5 BSE images obtained for a soap protrusion collected from the surface of the un-painted commercial pre-primed canvas roll (a). Detail of remaining lead white particles (b) and EDS map (c)

to the relatively young age of O'Keeffe's paintings and the early stage of the development of the soaps.
Ft-ir

FT-IR spectra were collected for both layers of the commercial pre-primed canvas paintings grounds and the single layer ground samples of the artist primed canvases, 

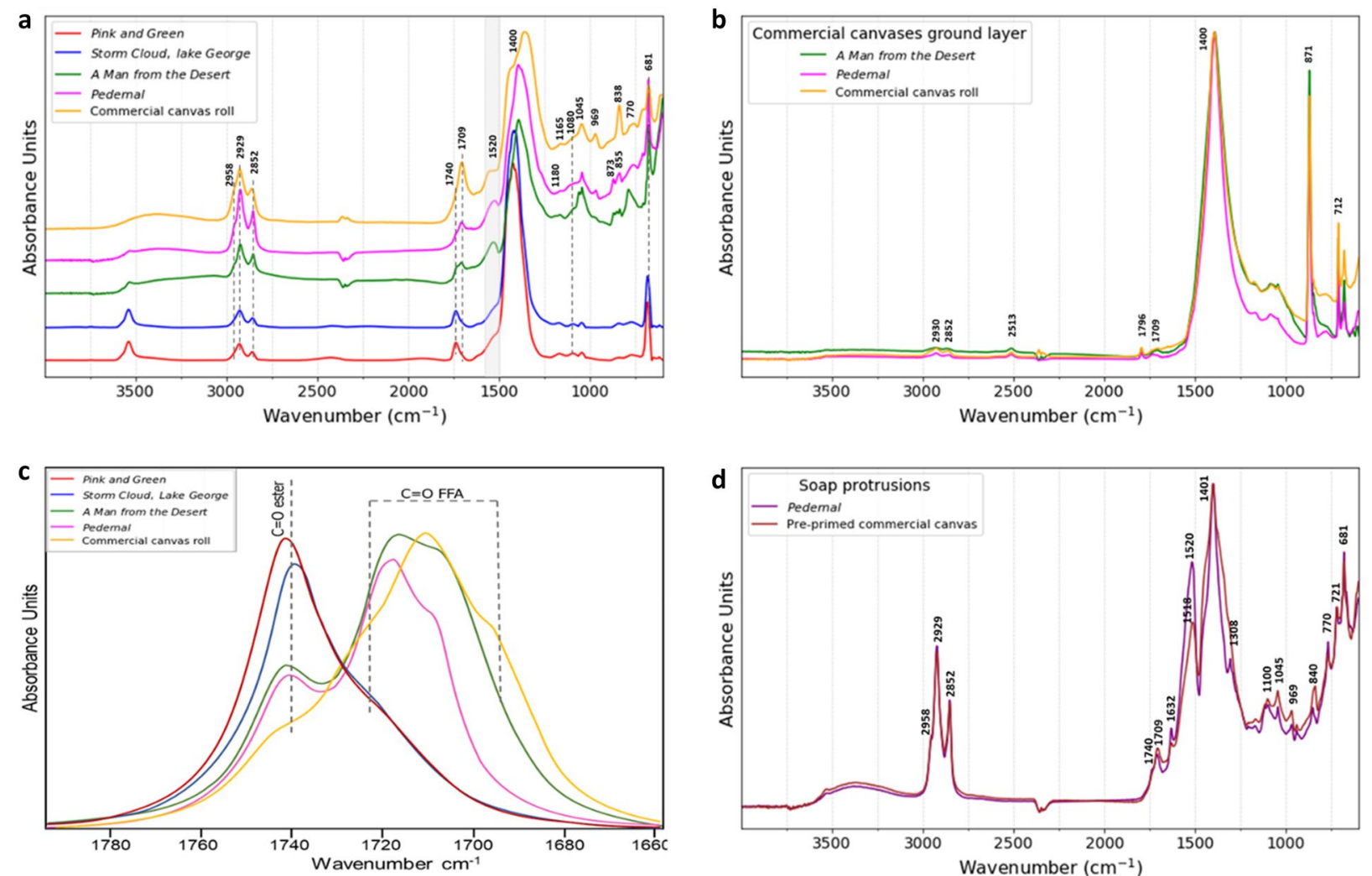

Fig. 6 a FT-IR spectra obtained for the preparation layer of A Man from the Desert, Pedernal and the commercial pre-primed canvas roll; artist primed canvas grounds (Pink and Green and Storm Cloud, Lake George). b FT-IR spectra obtained for the ground layer of the commercial canvases. c Detail of the IR bands in the region of 1800-1700 $\mathrm{cm}^{-1}$. $\mathbf{d}$ FT-IR spectra obtained for the soap protrusions from Pedernal and the commercial pre-primed canvas roll. All IR spectra were normalized to a single peak $\left(2929 \mathrm{~cm}^{-1}\right)$ and plotted offset for clarity

as well as for soap protrusion samples from Pedernal and the commercial pre-primed canvas roll. The main objective was to compare the FT-IR spectra of the different grounds to gain insights into their influence into the soap protrusion formation (Fig. 6). Representative spectra obtained for the ground layer of Pedernal, A Man from the Desert and the commercial canvas roll were identical and dominated by bands at 2513, 1796 and $1400\left(\mathrm{v} \mathrm{CO}_{3}{ }^{2-}\right), 871 \mathrm{~cm}^{-1}$ (out of plane bending $\mathrm{C}-\mathrm{O}$ ) and $712 \mathrm{~cm}^{-1}$ (in-plane bending $\mathrm{C}-\mathrm{O}$ ) characteristic of calcium carbonate $\left(\mathrm{CaCO}_{3}\right)$ (Fig. 6b). Also demarcated in Fig. 6 are weaker vibrational bands associated with the oil-based binding medium $\left(2958\left(\mathrm{vCH}_{3}\right), 2929\right.$ $\left(v \mathrm{CH}_{2}\right), 2852\left(v^{2} \mathrm{CH}_{3}\right), 1740\left(v_{\mathrm{as}} \mathrm{C}=\mathrm{O}\right) \mathrm{cm}^{-1}$. The spectrum obtained from the preparation layers of both paintings (Fig. 6a pink and green lines) exhibit very different features that may be ascribed to basic lead carbonate (hydrocerussite, $\left.\left.\left(\mathrm{PbCO}_{3}\right)_{2} \cdot \mathrm{Pb}(\mathrm{OH})_{2}\right)\right)$ at $3536(\mathrm{O}-\mathrm{H})$, $1400\left(v_{\mathrm{s}} \mathrm{C}-\mathrm{O}\right), 1045\left(v_{\mathrm{s}} \mathrm{C}-\mathrm{O}\right)$ and $681 \mathrm{~cm}^{-1}$ (in-plane bending $\mathrm{C}-\mathrm{O}$ ) along with oil-based medium. The band at $838 \mathrm{~cm}^{-1}$ assigned to the presence of neutral lead carbonate $\left(\mathrm{PbCO}_{3}\right.$, the mineral cerussite) is observed in the spectra obtained for the preparation layers [24]. Together these features indicate that there are just minor differences in the distribution and concentration of lead carbonate in the commercial canvas roll (Fig. 6a yellow line) and ground samples collected from Pedernal and A Man from the Desert (Fig. 6a pink and green lines). Other weak bands ascribed to barium sulfate $\left(\mathrm{BaSO}_{4}\right.$, the mineral barite) around 1180 and $1080 \mathrm{~cm}^{-1}$ were identified in the spectra of the commercial pre-primed canvas and the preparation layers of Pedernal and $A$ Man from the Desert. Variation in the intensity of these bands is likely due to the inhomogeneous distribution of the barite within the layer. These results are in accordance with a non-invasive study performed by Salvant et al. of similar works by O'Keeffe, where the co-occurrence of lead white, calcium carbonate, barium sulfate and lead soaps was reported [1]. In Fig. 6a, the spectra obtained for the artist prepared grounds from Pink and Green and Storm Cloud, Lake George (red and blue, respectively) are compared to the preparation layer of the commercial canvases. The spectra from Pink and Green and Storm Cloud, Lake George are dominated by bands 
characteristic of basic lead carbonate and the oil-based binding medium but possess none of the features indicate the formation of metal carboxylate soaps. In contrast, the most notable spectral feature from the preparation layers of A Man from the Desert, Pedernal, and the commercial pre-primed canvas is the band at $1520 \mathrm{~cm}^{-1}$ which indicates the presence of amorphous lead carboxylates (Fig. 6a) [18-21].

A broad shoulder at $2958 \mathrm{~cm}^{-1}\left(\mathrm{vCH}_{3}\right)$ in the spectra of the preparation layers of $A$ man from the Desert, Pedernal and the commercial pre-primed canvas is attributed to an increase of $\mathrm{CH}_{3}$ that could be caused by hydrolysis and fragmentation of the polymeric chain due to water from the ambient environment [32]. While it is important to consider exposure of the preparation layer to humidity as a mechanism that promotes the formation lead carboxylate soaps, we cannot discount the deliberate addition of fatty acid containing materials to the preparation layer formulation. This is supported in Fig. 6a where the spectra of the paintings with commercial pre-primed canvases have preparation layers that exhibits a band maximum around $1709 \mathrm{~cm}^{-1}$ characteristic of $v(C=O)$ in carboxylic acids associated with fatty acids not covalently bound to the polymerized oil network [22, 23]. When comparing this feature to same region of Pink and Green and Storm Cloud, Lake George (Fig. 6a) this band has its maximum at $1740 \mathrm{~cm}^{-1}$ and is associated with $v(\mathrm{C}=\mathrm{O})$ in a glyceryl ester form attached to the linseed oil network. ${ }^{4}$ Since the ground of Pink and Green and Storm Cloud, Lake George were prepared by artist using traditional methods, these spectra can be used as baseline for what would be expected from a typical ground medium prepared by the artist. The spectrum from the preparation layer of the commercial pre-primed canvas roll, in contrast, has a much higher free fatty acid content compared to the rest of the samples (yellow trace, Fig. 6a). Thus these spectral differences in the $v(C=O)$ IR band suggest a higher concentrations of free fatty acids in the commercially pre-primed canvases beyond what would be expected by hydrolysis alone.

To more thoroughly explore the free versus network bound carboxylate content of the commercial pre-primed canvas and the artist primed ground materials, the envelope region between 1800 and $1700 \mathrm{~cm}^{-1}$ was subjected to deconvolution and peak fitting analysis as shown in Fig. 6c. In this region, carbonyl stretching bands from both network bound glyceryl esters (RCOOR') and free fatty acids ( $\mathrm{RCOOH})$ may be observed as overlapping bands. As seen in the spectra from A Man from the

\footnotetext{
${ }^{4}$ The contribution of $v_{1}+v_{4}$ combination band of lead carbonate to the band $1740 \mathrm{~cm}^{-1}$ should be considered in all cases $[50,51]$.
}

Desert and Pedernal, the total peak area contribution of $\mathrm{C}=\mathrm{O}$ in the form of free fatty acid (bands at 1700 and $1710 \mathrm{~cm}^{-1}$ ), is higher than the contribution in glyceryl ester form [22, 24, 25]. Similar features were observed for the commercial pre-primed canvas roll in Fig. 4c where the contribution of $\mathrm{C}=\mathrm{O}$ in ester form is relatively low in comparison with the artist primed canvases used in Pink and Green and Storm Cloud, Lake George. In the case of the commercial pre-primed canvas roll sample, a small shoulder at around $1726 \mathrm{~cm}^{-1}$ associated with an aldehyde $\mathrm{C}=\mathrm{O}$ was identified, which contributes to the broadening of the carbonyl band. Acids and aldehydes are known degradation products of linseed oil [22, 24, $25,44,45]$. In contrast, the $\mathrm{C}=\mathrm{O}$ band with maximum at $1740 \mathrm{~cm}^{-1}$ in the spectra of the artist primed canvas grounds (Pink and Green as well as Storm Cloud, Lake George) indicate that the $\mathrm{C}=\mathrm{O}$ contribution in network bound esters is significantly higher than the contribution of $\mathrm{C}=\mathrm{O}$ in the form of fatty acids. These results are in accordance with the absence of soap protrusions in Pink and Green and Storm Cloud, Lake George. The presence of higher amounts of $\mathrm{C}=\mathrm{O}$ in form of free fatty acid can be due to: hydrolysis of glycerol esters within the oil network, the presence of a not chemically treated oil, and/ or to the presence of additives (e.g. metal stearates) in the commercial pre-primed canvas grounds.

As has been shown by previous studies $[18,26]$, a broad band with maximum centered around $1520 \mathrm{~cm}^{-1}$ is commonly associated with amorphous lead carboxylates. While these studies are based on pure materials and controlled experimental conditions that cannot be applied directly to real paint samples, they do inform the chemical reactions occurring in complex modern oil paintings. For example, [26] showed that the presence of saturated fatty acids (SFAs) and metal ions is a sufficient condition for crystalline metal soaps to form. Therefore, that a $1520 \mathrm{~cm}^{-1}$ feature is observed both in the protrusions aggregate of Pedernal and the commercial pre-primed canvas (Fig. 6d purple and red lines), suggest that the protrusions in Georgia O'Keeffe paintings may currently be mostly in an amorphous phase, but with potential crystallization of the soap material occuring over time. The spectra of the protrusions contain several unattributed bands (at 1632, 1308, 1102, 969, 840 and $770 \mathrm{~cm}^{-1}$ (labelled in Fig. 6d) in addition to the bands from lead soaps. While not conclusively identified, these bands could suggest the presence of oxalate and sulfate components $[48,49]$. Soap protrusions aggregates can remain active and the process to reach a stable end stage depends on several factors: the composition of the paint, the availability of fatty acids, environmental pollutants as well as environmental conditions $[6,7,17,52]$. The presence of these oxidation products suggests an inherent instability 


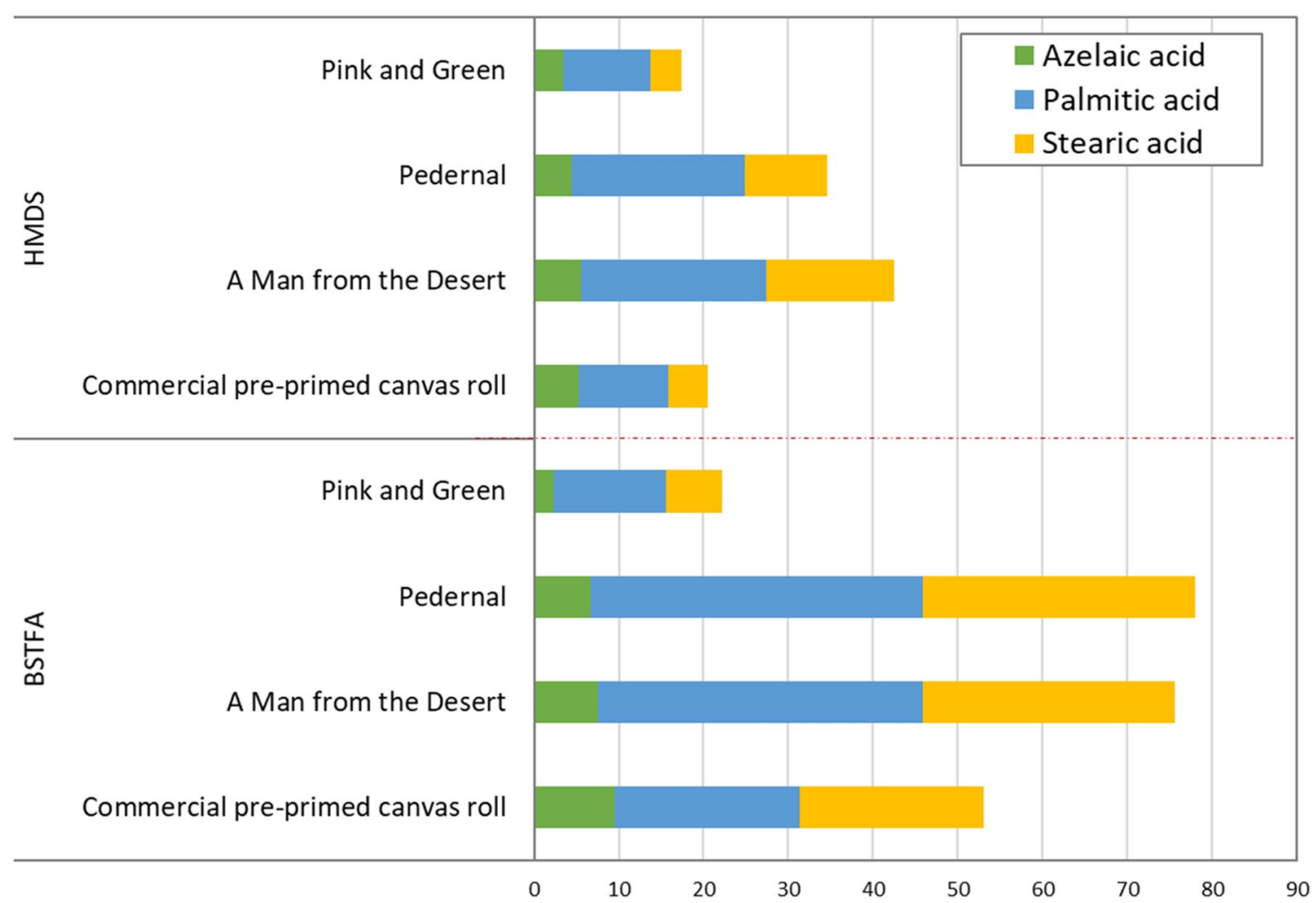

Fig. 7 Ratio of the area of peaks of trimethylsilyl fatty acids (azelaic, palmitic and stearic) to area of the sum of the trimethylsilyl fatty acids (azelaic, palmitic and stearic) obtained for the ground samples of Pink and Green, Pedernal, A Man from the Desert and the commercial canvas roll derivatized with HMDS and BSTFA. The results were normalized to the internal standard (tridecanoic acid)

of the paint and therefore particular attention should be taken regarding the storage conditions and during possible cleaning actions.

\section{Gc-ms}

The relative amounts of free fatty acids in the oil network vs. fatty acids carboxylates (metal carboxylates) may be discerned through fatty acid profiles obtained by means of GC-MS analysis. Fragments from the samples were extracted and derivatized by two different trimethylsilyl derivatization reagents: 1,1,1,3,3,3-hexamethyldisilazane (HMDS) and N,O-bis(trimethylsilyl)trifluoroacetamide (BSTFA) where HMDS induces silylation of free fatty acids present in the oil binding medium. BSTFA, on the other hand, will silylate all fatty acids present in the sample including free fatty acids and metal carboxylates [27-30]. The use of these two derivatization agents can qualitatively determine the metal carboxylate and the free fatty acid content in the ground samples. Figure 7 reports the results obtained from the HMDS and BSTFA derivatization methods, showing an estimated relative response of the trimethylsilyl fatty acids and metal carboxylates present in the ground samples compared to the total of the fatty acids (azelaic, palmitic and stearic acids) content.

What may be immediately discerned from Fig. 7 is that the artist-prepared ground used in Pink and Green has a much lower concentrations (based on peak height) of total palmitic and stearic acids than that of the commercial pre-primed canvases. This result could mean either that there is a lower amount of oil medium overall in Pink and Green (which is inconsistent with our visual observations of this work), or that a lower proportion of the medium is in the form of free acids or soaps. Based on the FTIR results, and the fact that the priming layers in all cases are based on lead white, it seems very likely that a lower proportion of the medium in the ground for Pink and Green is in the form of free acids or soaps. Comparison of the BSTFA and HDMS results in Figs. 7 and 8 indicates that there is a higher contribution of metal soaps as compared to free fatty acids in commercial pre-primed canvases vs. the artist-prepared ground. This is consistent with the FTIR results, which showed the presence of lead soaps in the commercial pre-primed canvases but not in the artist-prepared grounds. In addition, for the three commercial pre-primed ground samples, Fig. 7 shows 

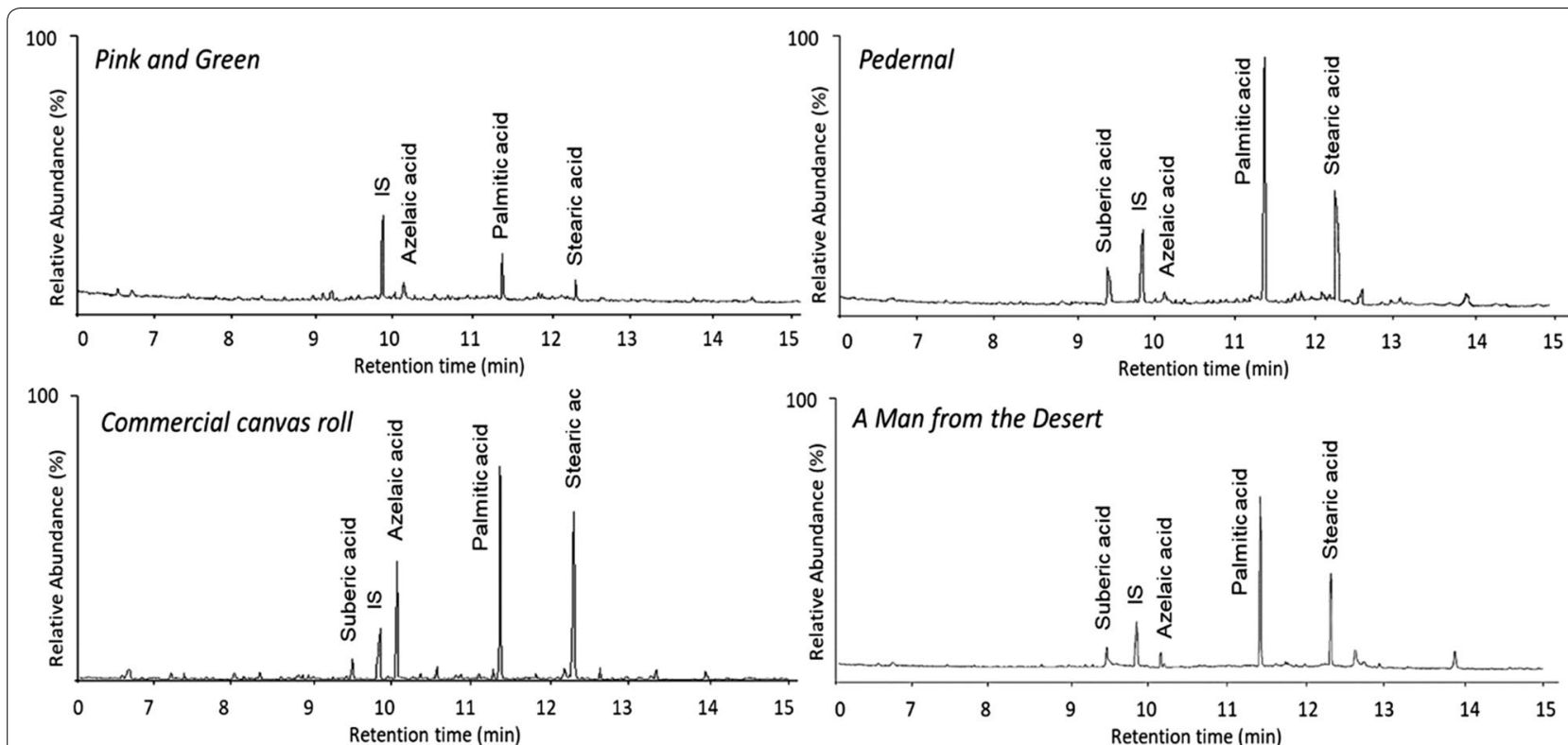

Fig. 8 GC-MS chromatograms obtained for Pink and Green, Pedernal, A Man from the Desert and the commercial canvas roll samples after derivation with BSTFA

that there is a higher proportion of stearic acid in the soap fraction as compared to the free fatty acid fraction.

Formation of metal soaps is commonly believed to be the consequence of the hydrolyzed oil, followed by reaction with the metal ions from the pigment $[7,33]$. However, soap protrusions can be also be produced by hydrolysis of additives [34, 35]. Our FT-IR results showed that the relative amount of fatty acids saponified in the pre-primed commercial canvas grounds was much higher than the amount of free fatty acids presents in the artistprepared canvas ground. A possible explanation, based on the high amounts of metal carboxylates identified by means of GC-MS, is that the metal carboxylates were part of the formulation of the commercial pre-primed grounds $[12,36]$. One hypothesis that may explain the presence of the soap protrusions is that these metal carboxylates were added to the commercially primed canvas formulation which has the deleterious effect of making the artists material more reactive and susceptible to external conditions (e.g. environmental conditions and conservation treatments) [12-15]. The growth process of the lead soap protrusions requires sufficient free fatty acids to migrate through the multilayered paint system [33]. The paintings studied here are also varnished. Hence, absorption of environmental moisture probably occurs from the back. A combination of moisture absorption from the back of the canvas, combined with the excess of FFA and the porosity of the preparation layer (observed in the SEM images), facilitates migration of the metal ions and SFAs from the ground to the upper layers. Once the lead soaps are in the upper layer, that is likely rich in additives due to the formulation of this modern paint, they can crystallize and aggregate, creating the soap protrusions.

\section{Conclusions}

In a series of Georgia O'Keeffe oil paintings from 1924 to 1950 an advanced degradation phenomenon was found to be related to a high concentration of lead soaps protrusions. The aim of this study was to characterize samples of the ground layer of O'Keeffe paintings from different periods of production, in an attempt to understand the condition of the Georgia O'Keeffe oil painting's due to the presence of lead soap protrusions.

The results obtained in this study have provided useful information regarding the composition of commercial twentieth century canvases used by O'Keeffe. We found significant differences between the composition of commercial pre-primed and artist primed canvas grounds: (i) the number of layers in the canvases grounds, (ii) the "breccia-like" aspect of the preparation layer and (iii) the pigment composition and size/ distribution. Qualitative GC-MS analysis demonstrates a high response of unsaturated fatty acids in the preparation layer of the pre-primed commercial canvas. These constituents in the commercially primed canvases together with the porosity ("breccia-like" aspect) of the preparation layer observed by means of SEM plays a crucial role in the vulnerability of the painted surfaces for the formation of lead soaps protrusions. A 
comparison of O'Keeffe paintings from different periods suggest that the formation of the lead soaps protrusions in O'Keeffe paintings is likely explained by the material composition of the preparation layers and its interaction with the upper layers.

In the two 1941 paintings (Pedernal and A Man from the Desert) painted on pre-primed commercial canvas, lead carboxylates have aggregated and developed into mechanically damaging and visual compromising lead soap protrusions. Analysis by FT-IR showed a broad IR absorption band at $1520 \mathrm{~cm}^{-1}$ suggesting that lead soaps in Georgia O'Keeffe oil paintings are also present in an amorphous state, and GC-MS data indicated that the protrusions contain primarily lead palmitate and lead stearate $[8,18,26]$. Based on FT-IR data, and the appearance of new soap protrusion in retouched areas we can suggest that lead carboxylates in Georgia O'Keeffe oil paintings will continue to actively form.

Our results facilitate a better understanding how commercially prepared grounds were used by Georgia O'Keeffe and can be related to the poor stability and durability of a number of her paintings. O'Keeffe's case is of relevance because the artist deliberately changed her technique and decided to use a different type of canvas in a crucial moment of her career, initiated by the increasing demand for her paintings. The artist stopped preparing her own canvases, made with lead white and linseed oil, due to the higher demand for her work. Instead, during the period of 1923-1946, she used a commercial pre-primed canvas that based on our study was rich in metal carboxylates and like the root cause of the reactivity of the paintings produced in this period. Knowledge of the compounds identified in the commercial canvases presented here and deterioration phenomena related to them is indispensable for the decision-making process in the design of conservation treatments for modern oil paintings. The findings presented here can be considered in the development of future studies of soap protrusion formation.

\section{Materials and methods}

\section{Sample locations and preparation}

Table 1 show the list of samples included in this study. Paint fragments were embedded in Buehler Epo Thin 2 epoxy and prepared as cross sections using ultramicrotomy to cut away excess resin and expose the fragment surface. While embedded paint fragments are usually polished by hand, microtomy was used to minimize damage to the soap protrusion complexes that are known to be soft and water sensitive [37, 38]. Additional small fragments of unmounted samples were analyzed using a combination of the techniques described below.

\section{Optical microscope}

Optical microscopy was primarily utilized for initial examination and photo-documentation of the study group samples. Samples prepared as cross section were characterized using a Wild M3Z Type S optical microscope.

\section{Environmental scanning electron microscopy}

Secondary electron images were obtained using a FEI Quanta 650 ESEM scanning electron microscope integrated with a Schottky field emission gun for high resolution and excellent beam stability and an Oxford AZtec EDS microanalysis system. The analytical conditions were low vacuum, 15 and $20 \mathrm{kV}$ accelerating voltage and a working distance of $10 \mathrm{~mm}$. Samples were directly observed in order to avoid interference with the particulate structure of the coating element used for eliminating charging effects.

\section{Fourier transform infrared spectroscopy}

IR spectra were collected by using a Bruker LUMOS FT-IR Microscope in Attenuated Total Reflectance (ATR) mode averaging together 32 scans at a resolution of $4 \mathrm{~cm}^{-1}$ in the mid-infrared region $\left(4000-500 \mathrm{~cm}^{-1}\right)$. During the infrared analysis, the sample was brought into contact with the tip of the Germanium (Ge) ATRcrystal $(100 \mu \mathrm{m}$ in diameter) on the predefined measurement position. The spot size was adjusted to $50 \mu \mathrm{m}$. Spectra were processed using the OPUS 5.0 version IR software.

\section{Data processing method}

For performing the determination of the carbonyl stretching bands contribution from triglyceride esters and free fatty acids in the samples, main features of the commonly used procedure including second derivative, and curve fitting analysis were applied [39-41] to semiquantitatively determine the content of functional groups $[42,43]$. The position of overlapped IR bands that appear as shoulders of most intense bands in the IR absorption spectra were made to correspond to the frequency of the minima in the second derivative of the spectra with a nine-point Savitsky-Golay smoothing filter. The selected band frequencies were used as initial parameters for curve fitting analysis. Prior to curve fitting, linear base line correction was subtracted from the $1800-1700 \mathrm{~cm}^{-1}$. In a second step, curve fitting analysis of the IR spectra covering the carbonyl groups region $\left(1800-1700 \mathrm{~cm}^{-1}\right)$ was performed using Lorentzian line shape. Curve fitting analysis was performed using a bandwidth at half height 
Table 1 Summary with the paintings analyzed in this study

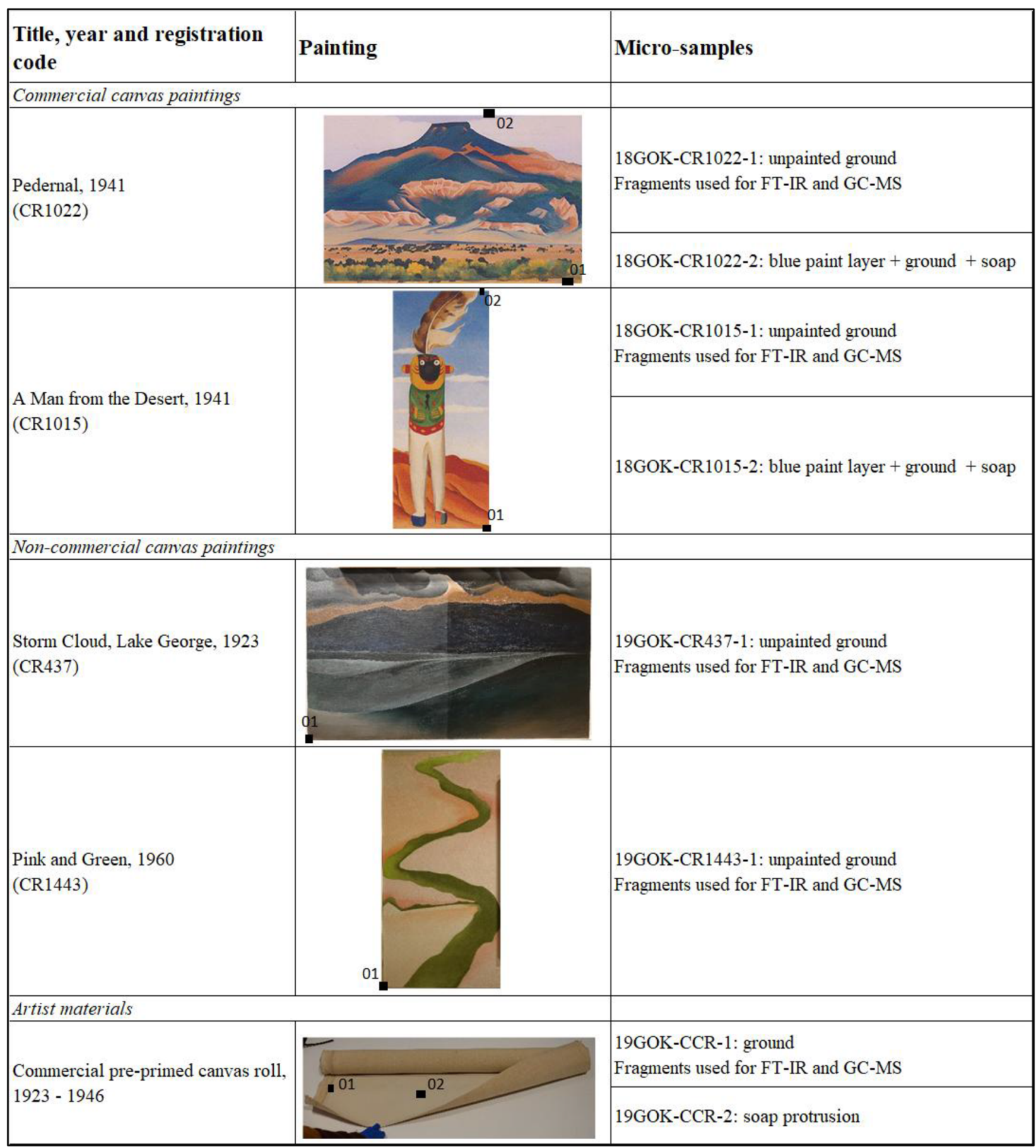

of $13 \mathrm{~cm}^{-1}$ and a resolution enhancement factor of 2.4 (these values were constant). These values were selected to avoid possible random noise artefacts indistinguishable from the carbonyl bands.

\section{Gas chromatography-mass spectrometry} Chemicals

Reagent grade palmitic acid, azelaic acid, oleic acid, and stearic acid $\geq 95 \%$ were obtained from Acros Organics, Sigma-Aldrich and EMD Millipore and its composition was confirmed by FT-IR. 
Absolute ethanol, acetone, diethyl ether, $n$-hexane and iso-octane (HPLC) grade, lead nitrate and stearic acid (purity $>99 \%$ ), hexadecane, tridecanoic, hexadecenoic and octadecanoic acid (purity 99\%), (N,Obis(trimethylsilyl)trifluoroacetamide (BSTFA) containing 1\% trimethychlorosilane (TMCS) and 1,1,1,3,3,3-hexamethyldisilazane (HMDS) were all purchased from SigmaAldrich (U.S.A.). Standard solutions were prepared in acetone (azelaic acid $4.06 \mu \mathrm{g} / \mathrm{g}$, palmitic acid: $4.39 \mu \mathrm{g} / \mathrm{g}$, and stearic acid: $6.62 \mu \mathrm{g} / \mathrm{g}$ ). Internal standard tridecanoic acid solution was prepared in iso-octane $140 \mu \mathrm{g} / \mathrm{g}$.

\section{Sample treatment}

Derivatization of metal soaps and free fatty acids with BSTFA containing 1\% trimethylchlorosilane.

Samples $(10 \mu \mathrm{g})$, were derivatized according to the conditions described in Nasa et al. [30], using $5 \mu \mathrm{L}$ of the tridecanoic acid solution (internal standard for derivatization). The mixture was dried under nitrogen flow at room temperature, and subsequently added with 20 $\mu \mathrm{L}$ of BSTFA and $150 \mu \mathrm{L}$ of $i$ so-octane. The reaction time and temperature were set at $81 \mathrm{~min}$ and $78^{\circ} \mathrm{C} .5 \mu \mathrm{L}$ of the $n$-hexane were added just before injection.

\section{Derivatization of free fatty acids with HMDS}

Samples $(10 \mu \mathrm{g})$ were added with $5 \mu \mathrm{L}$ of tridecanoic acid solution (internal standard for derivatization), and then dried under nitrogen flow at room temperature in order to remove the solvent. The residual solid was subjected to derivatization for the GC-MS analysis with $20 \mu \mathrm{L}$ of HMDS, $150 \mu \mathrm{L}$ of iso-octane at $60{ }^{\circ} \mathrm{C}$ for $30 \mathrm{~min} .5 \mu \mathrm{L}$ of the $n$-hexane were added just before injection.

The injection volume for all samples was $1 \mu \mathrm{L}$.

\section{Gas chromatography mass spectrometry}

GC-MS instrumentation consisted of a Thermo Trace GC-DSQII with a 5972 Mass Selective Detector singlequadrupole mass spectrometer.

Samples were injected in splitless mode and injector was set at $280{ }^{\circ} \mathrm{C}$. GC separation was performed on a fused silica capillary column TR-5MS (nonpolar phase; $5 \%$ phenyl polysilphenylene-siloxane). Chromatographic conditions were initial temperature $80{ }^{\circ} \mathrm{C}, 2 \mathrm{~min}$ isother$\mathrm{mal}, 20^{\circ} \mathrm{C} / \mathrm{min}$ up to $280^{\circ} \mathrm{C}, 10 \mathrm{~min}$ isothermal.

MS parameters: electron impact ionization (EI, $70 \mathrm{eV}$ ) in positive mode; ion source temperature $230{ }^{\circ} \mathrm{C}$; chromatograms were acquired simultaneously in full scan (range $50-650 \mathrm{~m} / \mathrm{z}$ ) and interface temperature $280{ }^{\circ} \mathrm{C}$. Retention time and corresponding mass spectra were used for compound identification, retention times were obtained for a series of standards of the most significant fatty acids (palmitic, stearic, azelaic and oleic). Xcalibur software and NIST libraries were used for identification of compounds and data analysis.

\section{Supplementary information}

Supplementary information accompanies this paper at https://doi. org/10.1186/s40494-020-00451-7.

Additional file 1: Figure S1. Supplementary information including the SEM-EDX maps obtained for Pedernal (1941), A Man from the Desert (1941), pre-primed commercial canvas, Pink and Green (1960), Storm Cloud, Lake George (1923) ground samples as well as FTIR spectra obtained for the paint layer of Pedernal and a detail of the $1380-1050 \mathrm{~cm}^{-1}$ region in the ATR-FT-IR spectrum of the soap protrusion sample from Pedernal (1941).

\section{Abbreviations}

SEM-EDX: Scanning electron microscopy coupled to energy dispersive X-ray; EDX: Energy dispersive X-ray; FTIR: Fourier transform infrared spectroscopy; GC-MS: Gas chromatography coupled with mass spectrometry; BSE: Backscattered electron; FFA: Free fatty acids; SFAs: Saturated fatty acids; HMDS: 1,1,1,3,3,3-hexamethyldisilazane; BSTFA: N,O-bis(trimethylsilyl)trifluoroacetamide; P/S: Palmitic vs. stearic ratio; MS: Mass spectra.

\section{Acknowledgements}

The collaborative initiative was made possible by support from the National Endowment for the Humanities (Metal Soap Protrusions on Georgia O'Keeffe's Paintings; PR-25890018). We also wish to thank the NUANCE Center which is supported by the NSF funded program in Nanoscale Science and Engineering Center (NSF-NSEC) as well as Neal Blair and Jieun Kim from the Civil and Engineering Department, Northwestern University, for use of the GC-MS facilities. Stephanie Zaleski (Center of Scientific Studies in the Arts) and Amra Aksamija (Art Institute of Chicago) contributed to helpful discussions about the role of soaps in painted works of art.

\section{Authors' contributions}

ASOM participated in the research design and coordination of the study, analysis, data interpretation and writing of the manuscript. MW contributed to the design and coordination of the study, and to the discussion and writing of the manuscript. DK contributed to the coordination of the study, discussion and writing of the manuscript. All authors read and approved the final manuscript.

\section{Funding}

The financial support of the NEH Grant and the Andrew W. Mellon Foundation is also gratefully acknowledged.

\section{Availability of data and materials}

The datasets used and/or analyzed during the current study are available from the corresponding author on reasonable request.

\section{Competing interests}

All authors declare that they have no competing interest.

\section{Author details}

${ }^{1}$ Center for the Scientific Studies in the Arts, Northwestern University, Evanston, IL, USA. ${ }^{2}$ Georgia O'Keeffe Museum, Santa Fe, NM, USA.

Received: 7 May 2020 Accepted: 15 October 2020

Published online: 28 October 2020

\section{References}

1. Salvant J, Walton M, Kronkright D, Yeh CK, Li F, Cossairt O, Katsaggelos A. Photometric stereo by UV-induced fluorescence to detect protrusions on Georgia O'Keeffe's paintings. In: Casadio F. et al. editors. Metal Soaps in Art. Cultural Heritage Science. Cham: Springer, 2019. p. 375-391. 
2. Lazzari M, Chiantore O. Drying and oxidative degradation of linseed oil. Polym Degrada Stab. 1999;65:303-13.

3. Mallégol J, Lemaire J, Gardette JL. Drier influence on the curing of linseed oil. Prog Org Coat. 2000;9:107-13.

4. Oakley LH, Casadio F, Shull KR, Broadbelt LJ. Microkinetic modeling of the autoxidative curing of an alkyd and oil-based pant model system. Appl Phys A. 2015;121:869-78.

5. Cotte $M$, Checroun E, NolfW, Taniguchi Y, Viguerie L, Burghammer M, Walter P, Rivard C, Salomé M, Janssens K, Susini J. Lead soaps in paintings: friends or foes? Stud Conserv. 2017;62:2-23.

6. Cotte M, Checroun E, Susini J, Walter P. Micro-analytical study of interactions between oil and lead compounds in paintings. Appl Phys A Mater Sci Process. 2007;89:841-8.

7. Hermans JJ, Keune K, Van Loon A, ledema PD. The crystallization of metal soaps and fatty acids in oil paint model systems. Phys Chem Chem Phys. 2016:18:10896-905.

8. Martínez-Casado FJ, Rodríguez-Cheda JA, Ramos-Riesco M, RedondoYélamos Ml, Cucinotta F, Fernández-Martínez A. Physicochemistry of pure lead (II) soaps: crystal structures, solid and liquid meso phases, and glass phases-crytallographic, calorimetric, and pair distribution function analysis. In: Casadio F. et al. editors. Metal Soaps in Art. Cultural Heritage Science. Cham: Springer, 2019. p. 227-239.

9. Noble P, Wadum J, Groen K, Heeren R, van den Berg KJ. Aspects of 17th century binding medium: inclusions in Rembrant's Anatomy Lesson of Dr. Nicolaes Tulp. Art et Chimie, La Couleur: Actes Du Congrès; CNRS Editions, 2000. p. 126-129.

10. Noble P, Boon JJ, Wadum J. Dissolution, aggregation and protrusion: lead soap formation in 17th century grounds and paint layers. ArtMatters Netherlands Tech Stud Art. 2003. 46-61.

11. Mayer R. The artist's handbook of materials and techniques, vol 12-16. New York: Viking Press, 1970. p. 125-222.

12. Zucker J. From Ground up: the Ground in 19th century American Pictures. J Am Inst Conserv. 1999;38:3-20.

13. Doerner M. The materials of artists and their use in painting. San Diego/ New York/London: Harvest; 1984.

14. Tumosa CS, Mecklenburg MF. The influence of lead ions on the drying oils. Stud Conserv. 2005;50:39-47.

15. Izzo FC. 20th century artists' oil paints: a chemical-physical survey. PhD dissertation in Chemical Sciences, Ca' Foscari University of Venice.

16. Keune K. Binding medium, pigments and metal soaps characterized and localized in paint cross sections, PhD Thesis, University of Amsterdam. Amsterdan: Report 11 of MOLART Series, AMOLF; 2005

17. Noble P, Boon JJ. Metal soap degradation of oil paintings: aggregates, increased transparency and efflorescence. In: Pakin MH, Thomson-Shore D. editors AIC Paintings Working Group Meeting 2006 Postprints, 2007. p. $1-5$.

18. Hermans JJ, Keune K, van Loon A, Corkery RW, ledema PD. Ionomer- like structure in mature oil paint binding media. RSC Adv. 2016;6:93363-9.

19. Cotte M, De Viguerie L, Checroun E, Susini J, Walter P. Historical Evolutions of Lead-Fat/Oil Formula from Antiquity to Modern Times in a Set of European Pharmaceutical and Painting Treatises. In: Casadio F. et al. editors. Metal Soaps in Art. Cultural Heritage Science. Cham: Springer, 2019. p. 85-106.

20. Catalano J, Murphy A, Yao Y, Zumbulyadis N, Centeno SA, Dybowski C. Understanding the Dynamics and Structure of Lead Soaps in Oil Paintings Using Multinuclear NMR. In: Casadio F. et al. editors. Metal Soaps in Art. Cultural Heritage Science. Cham: Springer; 2019. p. 69-84.

21. van den Berg KJ, Burnstock A, Schilling M. (2019) Notes on Metal Soap Extenders in Modern Oil Paints: History, Use, Degradation, and Analysis. In: Casadio F. et al. editors. Metal Soaps in Art. Cultural Heritage Science. Cham: Springer, 2019. p. 329-342.

22. Morsch S, van Driel BA, van den Berg KJ, Dik J. Investigating the photocatalytic degradation of oil paint using ATR-IR and AFM-IR. ACS Appl Mater Interfaces. 2017:9:10169-79.

23. van den Berg JDJ, Vermist ND, Carlyle L, Holcapek M, Boon JJ. Effects of traditional processing methods of linseed oil on the composition of its triacylglycerols. J Sep Sci. 2004;27:181-99.

24. van der Weerd J, van Loon A, Boon JJ. FTIR studies of the effects of pigments on the aging of oil. Stud Conserv. 2013;50:3-22.
25. Otero V, Sanches D, Montagner C, Vilarigues M, Carlyle L, Lopes JA, Melo $\mathrm{MJ}$. Characterisation of metal carboxylates by Raman and infrared spectroscopy in works of art. J Raman Spectrosc. 2014;45:1197-206.

26. Baij L, Hermans JJ, Keune K, ledema P. (2018) Time-dependent ATR-FTIR spectroscopic studies on fatty acid diffusion and the formation of metal soaps in oil paint model systems. Angew Chem Int. 2018;57:7351-4.

27. van den Berg JDJ, van den Berg KJ, Boon JJ. Determination of the degree of hydrolysis of oil paint samples using a two steps derivatization method on-column GC/MS. Prog Org Comp. 2001:41:143-55.

28. Doménech-Carbó MT, Kuckova S, de la Cruz-Cañizares J, Osete-Cortina L. Study of the influencing effect of pigments on the photoageing of terpenoid resins used as pictorial media. J Chromatogr A. 2006;1121:248-58.

29. La Nasa J, Lluveras- Tenorio A, Modugno F, Bonaduce I. Two-step analytical procedure for the characterization and quantification of metal soaps and resonates in paint samples. Heritage Sci. 2018;6:57.

30. La Nasa J, Modugno F, Aloisi M, Lluveras-Tenorio A, Bonaduce I. Development of a GC/MS method for the qualitative and quantitative analysis of mixtures of free fatty acids and metal soaps in paint samples. Anal Chim Act. 2018;1001:51-8.

31. Stols-Witlox M, Ormsby B, Gottsegen M. Grounds, 1400-1900. Including: Twentieth-century grounds. In: Stoner JH, Rushfield R. editors. Conservation of easel paintings. New York: Routledge, 2013. p. 153-188.

32. Modugno F, Di Gianvincenzo F, Degano I, van der Werf ID, Bonaduce I, van den Berg KJ. On the influence of relative humidity on the oxidation and hydrolysis of fresh and aged oil paints. Sci Rep. 2019;9:5533-49.

33. Keune K, Boon JJ. Analytical imaging studies of cross sections of paintings affected by lead soap aggregate formation. Stud Conserv. 2007;52:161-76.

34. Osmond G. Zinc white and the influence of paint composition for stability in oil based media. In: van den Berg K, et al., editors. Issues in Contemporary Oil Pain. Cham: Springer; 2014. p. 263-81.

35. Carlyle L. Paint driers discussed in 19th century British oil painting manuals. JAIC. 1999:38:69-82.

36. Hélou-de La Grandière P. A Montparnesse Disease? Severe manifestations of Metal soaps in paintings by Pierre Soulages from around 1959 to 1960 (Delaminating oil paint layers, medium exudates, discolorations). In: Casadio F. et al. editors. Metal Soaps in Art. Cultural Heritage Science. Cham: Springer, 2019. p. 393-412.

37. Banti D, Burnstock A, Bonaduce I, La Nasa J, Lee J, Lluveras-Tenorio A, Modugno F, Ormsby B, Jan van den Berg K. The influence of metal stearates on the water sensitivity of modern oil paints. In: van den Berg K. et al. editors. Conservation of Modern Oil Paintings. Cham: Springer. 2019. p. 451-463.

38. Burnstock A, van den Berg KJ, de Groot S, Wijnberg L. An Investigation of water-sensitive oil paints in twentieth-century paintings. In: Learner TJS, Smithen P, Krueger JW, Schilling MR, editors. Modern proceedings from the modern paints uncovered symposium. London: Tate Modern; 2008. p. 177-88.

39. García-Zubiri IX, González-Gaitano G, Sánchez M, Isasi JR. FTIR study of dibenzofuran-2-carboxylic acid and its complexes with $\beta$-cydodextrin. Vib Spectrosc. 2003;33:205-2013.

40. Le-Dréau F, Dupuy N, Artaud J, Ollivier D, Kister J. Infrared study of aging of edible oils by oxidative spectroscopic index and MCR-ALS chemometric method. Talanta. 2009;77:1748-56.

41. Duce C, Ghezzi L, Onor M, Bonaduce I, Colombini MP, Tine MR, Bramanti E. Physico-chemical characterization of protein-pigment interactions in tempera paint reconstructions: casein/cinnabar and albumin/cinnabar. Anal Bional Chem. 2012;402:2183-93.

42. Georgiev A, Karamancheva I, Topalova L. Determination of oxidation products in transformer oils using FTIR spectroscopy. J Mol Struct. 2008;872:18-23.

43. Mastandrea A, Guido A, Demasi F, Ruffolo SA, Russo F. The Characterisation of Sedimentary Organic Matter in Carbonates with Fourier-Transform Infrared (FTIR) Spectroscopy. In: Advances in Stromatolite Geobiology. Lecture Notes in Earth Sciences, vol 131. Berlin: Springer. 2011. p.331-342.

44. Modugno F, Di Gianvicenzo F, Degano I, Dorothé van der Werf I, Bonaduce I, van den Berg KJ. On the influence of relative humidity on the oxidation and hydrolysis of fresh and aged oil paints. Sci Rep. 2019. 9:5533-5549 
45. Baij L, Chassouant L, Hermans JJ, Keune K, ledema PD. The concentration and origins of carboxylic acid groups in oil paint. RSC Adv. 2019;9:3559-35564.

46. Dictionary, Merriam-Webster. Breccia. https://www.merriam-webst er.com/dictionary/breccia. Accessed 10 Jul. 2020

47. Carlyle L. Materials: Grounds and Supports. In: The Artist's Assistant. New York: Wiley \& Sons, 2009. p.172.

48. Rosi F, Cartechini L, Monico L, Gabrieli F, Vagnini M, Buti D, Doherty B, Anselmi C, Brunettu BG, Miliani C. Tracking Metal Oxalates and Carboxylates on Painting Surfaces by Non-invasive Reflection Mid-FTIR Spectroscopy. In: Casadio F. et al. editors. Metal Soaps in Art. Cultural Heritage Science. Cham: Springer. 2019. p. 173-193.

49. Salvadó N, Buti S, Pradell T, Beltran V, Cinque G, Juanhuix J. Identification and Distribution of Metal Soaps and Oxalates in Oil and Tempera Paint Layers in Fifteenth-Century Altarpieces Using Synchrotron Radiation Techniques. In: Casadio F. et al. editors. Metal Soaps in Art. Cultural Heritage Science. Cham: Springer. 2019. p. 195-210.
50. Miliani C, Rosi F, Daveri A, Brunetti BG. Reflection infrared spectroscopy for the non-invasive in situ study of artists' pigments. Apply Phys A. 2012;106:295-307.

51. Steger S, Stege H, Bretz S, Hahn O. Capabilities and limitations of handheld Diffuse Reflectance Infrared Fourier Transform Spectroscopy (DRIFTS) for the analysis of colourants and binders in 20th century reverse paintings on glass.

52. Noble P. A Brief History of Metal Soaps in Paintings from a Conservation Perspective. In: Casadio F. et al. editors. Metal Soaps in Art. Cultural Heritage Science. Cham: Springer, 2019. p. 1-22.

\section{Publisher's Note}

Springer Nature remains neutral with regard to jurisdictional claims in published maps and institutional affiliations.

\section{Submit your manuscript to a SpringerOpen ${ }^{\circ}$ journal and benefit from:}

- Convenient online submission

- Rigorous peer review

- Open access: articles freely available online

- High visibility within the field

- Retaining the copyright to your article

Submit your next manuscript at $\boldsymbol{\nabla}$ springeropen.com 